\title{
Laminin-5 is a biomarker of invasiveness in cervical adenocarcinoma
}

\author{
Johji Imura ${ }^{1 *}$, Yoshiaki Uchida ${ }^{2}$, Kazuhiro Nomoto ${ }^{1}$, Kazuhito Ichikawa ${ }^{3}$, Shigeki Tomita ${ }^{3}$, Tatsuo lijima ${ }^{2}$ \\ and Takahiro Fujimori ${ }^{3}$
}

\begin{abstract}
Background: Glandular lesions are often problematic for diagnostic cervical pathology. The survival of patients with adenocarcinoma is significantly poorer than that of patient with squamous cell carcinoma. One reason for this increased risk is the aggressive invasiveness of adenocarcinoma. Therefore additional biomarkers, to supplement morphological diagnosis of adenocarcinoma, are necessary. We have assessed the diagnostic utility of Laminin-5 (Laminin $\gamma 2$ chain): Lam-5 in the diagnosis of the invasiveness of cervical adenocarcinoma and related glandular lesions.
\end{abstract}

Methods: Lam-5 immunohistochemistry was performed on archival specimens from 8 patients with uterine leiomyoma as a negative control group, 6 patients with endocervical gland hyperplasia, 6 patients with adenocarcinoma in situ, 6 patients with microinvasive adenocarcinoma and 24 patients with invasive adenocarcinoma.

Results: The expression of Lam-5 was not detected in normal mucosa, but was seen along the basement membrane in endocervical gland hyperplasia and adenocarcinoma in situ and was observed in the cytoplasm of tumor cells in microinvasive and invasive adenocarcinoma.

Conclusion: We conclude that Lam-5 is a useful biomarker in the evaluation of invasiveness in cervical adenocarcinoma.

Virtual slides: The virtual slides for this article can be found here: http://www.diagnosticpathology.diagnomx.eu/vs/ 7316562925827381

Keywords: Cervical adenocarcinoma, Invasiveness, Laminin-5, Immunohistochemical analysis

\section{Background}

Although adenocarcinoma $(\mathrm{AC})$ is rare, relative to squamous cell carcinoma (SCC), among uterine cervical cancers, the number of cases has increased in recent years, particularly in young women [1]. Like SCC, invasive AC is associated with high-risk human papillomavirus infection and arises from non-invasive precursors, namely cervical glandular intraepithelial neoplasia/adenocarcinoma in situ [2]. The distinction between AC and SCC is not only of academic interest since these glandular lesions present many problems for diagnostic cervical

\footnotetext{
* Correspondence: imura@med.u-toyama.ac.jp

'Department of Diagnostic Pathology, Graduate School of Medicine and Pharmaceutical Sciences, University of Toyama, 2630 Sugitani, Toyama City, Toyama 930-0194, Japan

Full list of author information is available at the end of the article
}

pathology. Many different types of benign glandular lesions of the endocervix increase the potential for cervical neoplasia [3]. However, the distinguishing features of AC and SCC have practical therapeutic and prognostic implications, since the survival of patients with $\mathrm{AC}$ is significantly poorer than that for patients with SCC. The high invasiveness of tumor cells is the main reason for poor prognosis in AC. Many factors affect the invasiveness of tumors. A wide variety of molecular markers have been evaluated as diagnostic tools in the identification of high-risk precursors of SCC and AC and the association with cell adhesion molecules has attracted attention recently. These molecules affect the protein constitution of the basement membrane and play an important role in invasiveness.

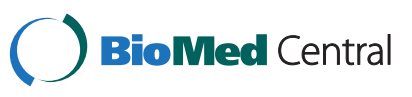


Laminin-5 (Laminin $\gamma 2$ chain): Lam-5 consists of extracellular proteins and is among the components of the basement membrane. The major functions of Lam-5 include binding of epithelial cells to the basement membrane through the formation of hemidesmosomes [4] and the migration of epithelial cells during wound repair $[5,6]$. In addition, it has been reported that there is a correlation between its expression and tumor progression in various kinds of malignant tumors [7-20]. According to some reports, Lam-5 is found in front-line invasive tumor cells at the epithelial-stromal interface and plays an important role in cancer cell invasion [9,11,12,17-23]. Accumulating data indicates that Lam5 expression can serve as a marker for invasiveness in carcinoma cells from different tissues $[18,19,23]$. In uterine cervical cancers, recent data suggests that expression of Lam-5 could be a useful marker in the detection of invasive squamous cell carcinoma [20]. A more interesting finding, perhaps is that Lam-5 seems to be expressed from the earliest stages, particularly in microinvasive lesions.

Lam-5 may therefore become a very useful biomarker of early invasion in the $\mathrm{AC}$ of the uterine cervix. The aim of the present study was to assess whether Lam-5 can be used for evaluation of tumor cell invasiveness in cervical AC and other precancerous lesions. We also investigated whether Lam-5 can be used as a marker of invasiveness in neoplastic lesions.

\section{Methods \\ Cases}

Each of our 50 cases were registered at the Department of Surgical and Molecular Pathology, Dokkyo University School of Medicine and the Department of Pathology, Ibaraki Prefectural Central Hospital and were available for clinicopathological and immunohistochemical analysis. The patients were staged clinically according to the criteria of the International Federation of Gynecology and Obstetrics: FIGO. Of the 42 tumors, 6 were glandular hyperplasia, 6 were adenocarcinoma in situ (TMN Stage 0), 6 were microinvasive adenocarcinoma (Stage Ia) and 24 were invasive carcinoma (Ib were 16 cases, II were 5 cases and III were 3 cases).

\section{Immunohistochemistry}

The control specimens were normal tissues from 8 cases of hysterectomy with diagnosis based on uterine leiomyoma. We selected routinely-processed, formalin-fixed, paraffin-embedded tissue blocks and prepared 5micrometer serial sections from the cut surface of the blocks. Mouse monoclonal antibody (clone D4B45, Chemicon 1:100) was used for the present immunohistochemical study. Immunoperoxidase reactions were performed using a Venta View automated immunostainer according to the manufacturer's instructions. All cases were reviewed by two investigators (JI and TF), and were provided with a consensus on the pathological diagnoses and the assessment of immunoreactivity.

\section{Results}

No expression of Lam-5 was seen in normal endocervical glands and surrounding stroma (Figure 1A). Two of 6 cases $(33 \%)$ of endocervical gland hyperplasia showed linear or focal basement membrane expression of Lam-5 (Figure 1B). Five of 6 (83\%) cases of 'adenocarcinoma in situ' showed continuous and linear Lam-5 expression along the basement membrane (Figure 1C). All of the 6 cases $(100 \%)$ of microinvasive adenocarcinoma produced a positive reaction, with expression mainly present at the invading front. Four of these cases evidenced cytoplasmic expression with the remainder linearly expressed along the basement membrane. Cytoplasmic expression was specifically seen in budding or dissociated cells from tumor nests. Eighteen of 24 cases (75\%) of invasive adenocarcinoma revealed cytoplasmic expression (Figure 1D). Cytoplasmic expression was diffuse in most tumor cells and scattered in the stroma. Linear expression along the basement membrane surrounding tumor cells was also observed in 11 of these cases. The immunohistochemical findings are summarized in Table 1.

\section{Discussion}

Laminins are a family of basement membrane proteins, which associate with cell differentiation proteins, adhesion and migration proteins, as well as being structural components themselves [24-26]. Lam-5 is a recently identified laminin isoform and is a disulfide-linked heterotrimer with precursor subunits of 200-, 155-, and $140-\mathrm{kDa}$. These precursors are rapidly processed by cleavage of the 200- and 155-kDa subchains into 165and $105-\mathrm{kDd}$ polypeptides, respectively [27]. Lam-5 is known to be expressed in squamous cell carcinoma, various adenocarcinomas and in organs such as the esophagus, cervix, breast, colon and pancreas [7-20]. An earlier study proposed that binding of the ligand to urinary-type plasminogen activator receptor: UPAR promotes cancer cell invasion by activation of plasminogen, leading to the degradation of extracellular matrix [28]. The coexpression of Lam-5 and UPAR suggested Lam-5 may be useful as a marker of invasion in some human cancers $[18,23]$. According to certain studies, Lam-5 is found at the invasive front, along the epithelial-stromal interface and plays an important role in cancer cell invasion [9,11,12,17-23]. Sordat et al. [23] and Pyke et al. $[17,18]$ observed budding cancer cells linked with the accumulation of Lam-5 in the cytoplasm. In contrast, extracellular Lam-5 expression has been reported in 


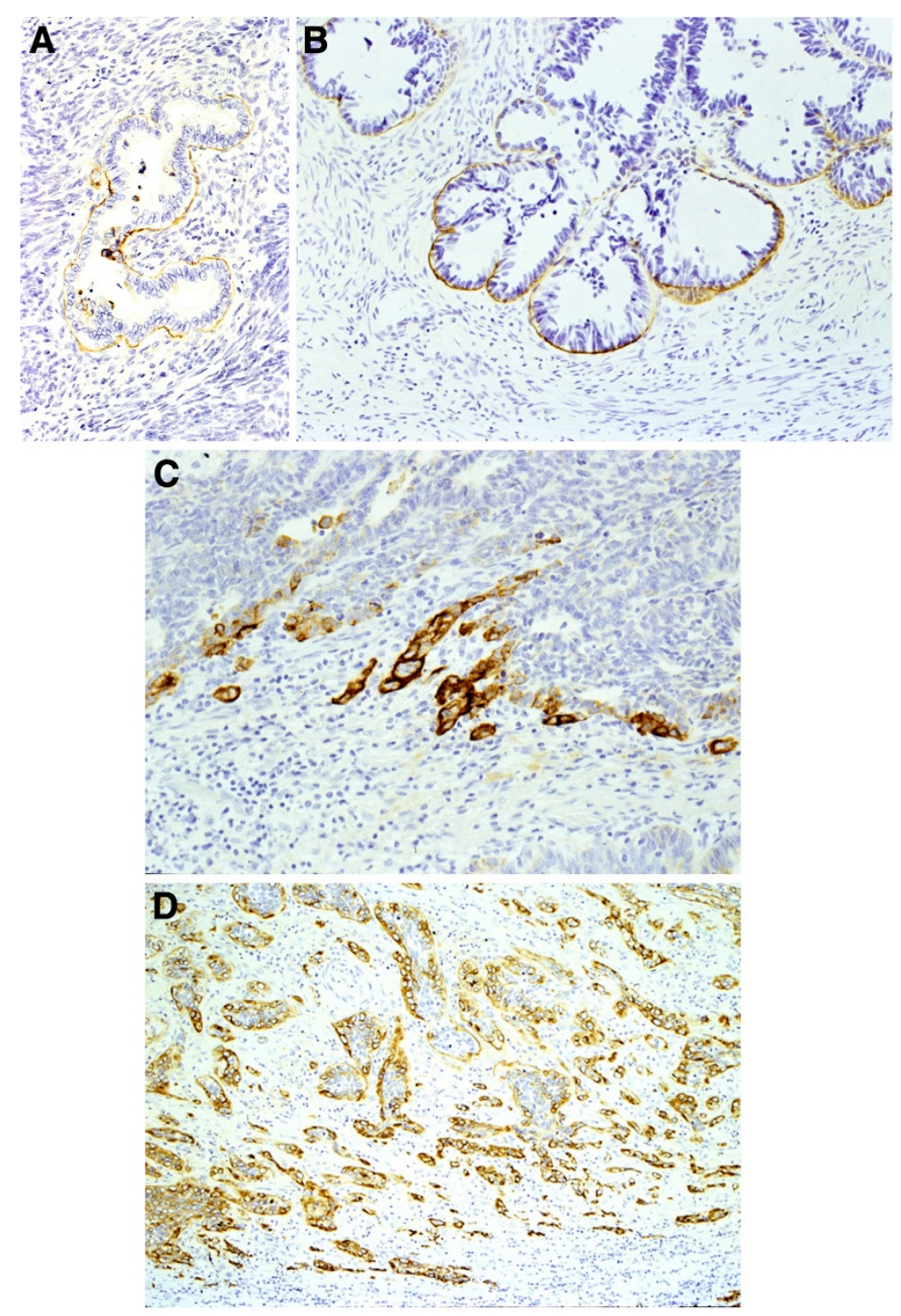

Figure 1 Immunohistochemical findings for Laminin-5 in the normal mucosa and the lesions of uterine cervix. A. Normal mucosa: No reaction in the endocervical glands. B. Endocervical gland hyperplasia and $\mathbf{C}$. Adenocarcinoma in situ: Continuous and linear expression along basement membrane. $\mathbf{D}$. Invasive adenocarcinoma: The diffuse immunoreactivity in most of tumor cells is scattered in the stroma.

gastric cancer and in basement membranes surrounding cancer cells [11].

Lam-5 is expressed in hyperplastic tissue and most tumors, but is not expressed in normal tissue. Although the expression of Lam-5 was shown in a few glands with endocervical hyperplasia, these cells might have already acquired tumor characteristics without morphological changes i.e. precursor cells derived from endocervical glands that expressed Lam-5 might acquire tumor characteristics.

Based on our results, we suggest that Lam-5 expression might be an early event during neoplastic progression towards AC. According to our hypothesis, the upregulation of expression of Lam-5 might be related to tumor progression, e.g. the adenoma-noninvasive carcinoma-invasive carcinoma sequence seen in colon carcinogenesis. It seems clear from the literature that structural changes in Lam- 5 are relatively early events during the development of invasiveness. On the other hand, the frequency of Lam-5 expression decreased, to $75 \%$ in invasive $\mathrm{AC}$ although it is $100 \%$ in microinvasive AC. This interpretation is difficult, but Lam-5 may be expressed at an early stage of the invasion. Furthermore the expression of Lam-5 might be attenuated in the later phases when tumor cells are more extensively invasive. Although the detailed molecular carcinogenic mechanism is unknown, it does seem to be related to Lam-5 expression and the acquirement of invasiveness. Several 
Table 1 Association between for laminin 5 y 2 chain immunohistochemical expression and glandular lesions

\begin{tabular}{lcccc}
\hline Histologic & Case & Expression & \multicolumn{2}{c}{ Lamin-5 } \\
\cline { 4 - 5 } & & & Linear & Cytoplasm \\
\cline { 4 - 5 } & & & 0 & 0 \\
Normal & 8 & 2 & 2 & 0 \\
Hyperplasia & 6 & 5 & 5 & 0 \\
Microinvasive & 6 & 6 & 2 & 4 \\
Invasive & 24 & 18 & 11 & 18
\end{tabular}

Normal: normal gland.

Hyperplasia: glandular hyperplasia.

AIS: adenocarcinoma in situ.

Microinvasive: microinvasive adenocarcinoma.

Invasive: invasive adenocarcinoma.

investigators have shown that the Lam-5 chain is expressed in epithelial cells at the invasive front of malignant tumors $[9,11,12,17-23]$. Other investigators also describe how Lam-5 could become a useful biomarker for the early detection of invasive tumor cells $[20,29,30]$.

Cervical cancer is the second most common malignancy in women worldwide [31]. Of the various histologic subtypes, SCC is by far the most common form while $\mathrm{AC}$ is relatively rare. In recent years, epidemiologic studies have shown an increasing incidence of AC worldwide [32], especially in younger patients $[1,33]$. AC is a highly aggressive gynecologic malignancy. Over the last several decades, the relative proportion of $\mathrm{AC}$ to SCC of the uterine cervix has been increasing with several studies reporting an increase in the absolute number of AC cases [34]. In uterine cervical neoplasia, there are many etiologies that explain why the AC patient has a poorer prognosis than that of SCC [35]. One is the high tendency for invasiveness of adenocarcinoma cells. It is often hard to diagnose by colposcopy, cytodiagnosis and punch biopsy, since AC tends to grow endophytically. With regard to diagnosis, differentiation between adenocarcinoma in situ (FIGO 0), microinvasive (Ia), and invasive adenocarcinoma (Ib) is an important and difficult question to answer. The treatment strategy for patients is different for adenocarcinoma in situ, microinvasive adenocarcinoma and invasive adenocarcinoma. The patient will receive disease-specific treatments e.g. conization in adenocarcinoma in situ, simple hysterectomy in microinvasive adenocarcinoma and radical hysterectomy with additional lymphadenectomy in invasive adenocarcinoma. It is often difficult to make this decision preoperatively. We conclude in this article that the immunohistochemistry of Lam-5 is effective as a means to solve this problem. Specifically, when cells expressing Lam-5 were observed in the lesion by biopsy, we are able to surmise that those cells are invasive. Therefore a simple hysterectomy and/or more extensive surgery is indicated for these patients. In addition, even if the lesion was non-invasive in CIS morphologically, these tumor cells might have acquired invasiveness when the cells express Lam-5. In such a case, intensive follow-up care is required after treatment by conization. Thus, a sensitive diagnostic procedure is a prerequisite for appropriate therapy.

\section{Conclusion}

It is only cases of microinvasive or invasive adenocarcinoma that have shown cytoplasmic immunoreactivity to Lam-5. These findings are similar to other reports that have compared immunoreactivity in different tumors, particularly cervical squamous neoplasia. Our results indicate that immunohistochemical expression of Lam-5 is a useful marker for detecting invasive tumor cells in AC. We can evaluate invasion in AC more precisely using Lam-5 immunohistochemistry as an adjunct to morphological examination. This method could be useful in the histopathological diagnosis of cervical cancer.

\section{Abbreviations}

Lam-5: Laminin-5 (Laminin ү2 chain); AC: Adenocarcinoma; SCC: Squamous cell carcinoma; FIGO: International Federation of Gynecology and Obstetrics; UPAR: Urinary-type plasminogen activator receptor.

\section{Competing interests}

No financial and non-financial competing interests to declare in relation to this manuscript.

\section{Authors' contributions}

\lrcorner was involved in the design of the study and immunohistochemical analysis, and drafted the manuscript. YU conceived the study, was involved in the design and immunohistochemical analysis, and edited the manuscript for intellectual content. KI, ST, TI and TF were involved in the design of the study and pathological diagnosis. All authors read and approved the final manuscript.

\section{Acknowledgements}

We thank Ms. Kaori Abe, Reiko Shimizu and Chiaki Matsuyama for technical assistance with the Lam-5 immunohistochemical analysis.

\section{Author details}

'Department of Diagnostic Pathology, Graduate School of Medicine and Pharmaceutical Sciences, University of Toyama, 2630 Sugitani, Toyama City, Toyama 930-0194, Japan. ²Department of Pathology, Ibaraki Prefectural Central Hospital, 6528 Koibuchi, Kasama, Ibaraki 309-1793, Japan.

${ }^{3}$ Department of Surgical and Molecular Pathology, Dokkyo Medical University School of Medicine, 880 Kitakobayashi, Mibu, Shimotsuga, Tochigi 321-0293, Japan.

Received: 7 August 2011 Accepted: 5 February 2012

Published: 17 August 2012

\section{References}

1. Hopkins MP, Morley GW: A comparison of adenocarcinoma and squamous cell carcinoma of the cervix. Obstet Gynecol 1991, 77:912-917.

2. Azodi M, Chambers SK, Rutherford TJ, Kohorn El, Schwartz PE, Chambers JT: Adenocarcinoma in situ of the cervix: management and outcome. Gynecol Oncol 1999, 73:348-353.

3. Jaworski RC: Endocervical glandular dysplasia, adenocarcinoma in situ, and early invasive (microinvasive) adenocarcinoma of the uterine cervix. Semin Diagn Pathol 1990, 7:190-204.

4. Sonnenberg A, de Melker AA, Martinez de Velasco AM, Janssen H, Calafat J, Niessen CM: Formation of hemidesmosomes in cells of a transformed murine mammary tumor cell line and mechanisms involved in 
adherence of these cells to laminin and kalinin. J Cell Sci 1993, 106(Pt 4):1083-1102

5. Goldfinger LE, Hopkinson SB, deHart GW, Collawn S, Couchman JR, Jones JC: The alpha3 laminin subunit, alpha6beta4 and alpha3beta1 integrin coordinately regulate wound healing in cultured epithelial cells and in the skin. J Cell Sci 1999, 112(Pt 16):2615-2629.

6. Zhang $\mathrm{K}$, Kramer RH: Laminin 5 deposition promotes keratinocyte motility. Exp Cell Res 1996, 227:309-322.

7. Giannelli G, Antonaci S: Biological and clinical relevance of Laminin-5 in cancer. Clin Exp Metastasis 2000, 18:439-443.

8. Haas KM, Berndt A, Stiller KJ, Hyckel P, Kosmehl H: A comparative quantitative analysis of laminin-5 in the basement membrane of normal, hyperplastic, and malignant oral mucosa by confocal immunofluorescence imaging. J Histochem Cytochem 2001, 49:1261-1268.

9. Hao J, Yang Y, McDaniel KM, Dalkin BL, Cress AE, Nagle RB: Differential expression of laminin 5 (alpha 3 beta 3 gamma 2) by human malignant and normal prostate. Am J Pathol 1996, 149:1341-1349.

10. Katayama M, Sekiguchi K: Laminin-5 in epithelial tumour invasion. J Mol Histol 2004, 35:277-286.

11. Koshikawa N, Moriyama K, Takamura H, Mizushima H, Nagashima Y, Yanoma S, Miyazaki K: Overexpression of laminin gamma2 chain monomer in invading gastric carcinoma cells. Cancer Res 1999, 59:5596-5601.

12. Maatta M, Soini $Y$, Paakko $P$, Salo S, Tryggvason $K$, Autio-Harmainen H: Expression of the laminin gamma2 chain in different histological types of lung carcinoma. A study by immunohistochemistry and in situ hybridization. J Pathol 1999, 188:361-368.

13. Miyazaki K: Laminin-5 (laminin-332): Unique biological activity and role in tumor growth and invasion. Cancer Sci 2006, 97:91-98.

14. Ono $Y$, Nakanishi $Y$, Ino $Y$, Niki T, Yamada T, Yoshimura K, Saikawa M, Nakajima T, Hirohashi S: Clinocopathologic significance of laminin-5 gamma2 chain expression in squamous cell carcinoma of the tongue: immunohistochemical analysis of 67 lesions. Cancer 1999, 85:2315-2321.

15. Patarroyo M, Tryggvason $K$, Virtanen I: Laminin isoforms in tumor invasion, angiogenesis and metastasis. Semin Cancer Biol 2002, 12:197-207.

16. Patel V, Aldridge K, Ensley JF, Odell E, Boyd A, Jones J, Gutkind JS, Yeudall WA: Laminin-gamma2 overexpression in head-and-neck squamous cell carcinoma. Int J Cancer 2002, 99:583-588.

17. Pyke C, Romer J, Kallunki P, Lund LR, Ralfkiaer E, Dano K, Tryggvason K: The gamma 2 chain of kalinin/laminin 5 is preferentially expressed in invading malignant cells in human cancers. Am J Pathol 1994, 145:782-791.

18. Pyke C, Salo S, Ralfkiaer E, Romer J, Dano K, Tryggvason K: Laminin-5 is a marker of invading cancer cells in some human carcinomas and is coexpressed with the receptor for urokinase plasminogen activator in budding cancer cells in colon adenocarcinomas. Cancer Res 1995, 55:4132-4139.

19. Soini Y, Maatta M, Salo S, Tryggvason K, Autio-Harmainen H: Expression of the laminin gamma 2 chain in pancreatic adenocarcinoma. J Pathol 1996, 180:290-294.

20. Skyldberg B, Salo S, Eriksson E, Aspenblad U, Moberger B, Tryggvason K, Auer G: Laminin-5 as a marker of invasiveness in cervical lesions. J Natl Cancer Inst 1999, 91:1882-1887.

21. Tani T, Lumme A, Linnala A, Kivilaakso E, Kiviluoto T, Burgeson RE, Kangas L, Leivo I, Virtanen I: Pancreatic carcinomas deposit laminin-5, preferably adhere to laminin-5, and migrate on the newly deposited basement membrane. Am J Pathol 1997, 151:1289-1302.

22. Gagnoux-Palacios L, Allegra M, Spirito F, Pommeret O, Romero C, Ortonne $J P$, Meneguzzi G: The short arm of the laminin gamma2 chain plays a pivotal role in the incorporation of laminin 5 into the extracellular matrix and in cell adhesion. J Cell Biol 2001, 153:835-850.

23. Sordat I, Bosman FT, Dorta G, Rousselle P, Aberdam D, Blum AL, Sordat B: Differential expression of laminin-5 subunits and integrin receptors in human colorectal neoplasia. J Pathol 1998, 185:44-52.

24. Gasparoni A, Della Casa M, Milillo L, Lorenzini G, Rubini C, Urso R, Lo Muzio $L$ : Prognostic value of differential expression of Laminin-5 gamma2 in oral squamous cell carcinomas: correlation with survival. Oncol Rep 2007, 18:793-800

25. Giannelli G, Falk-Marzillier J, Schiraldi O, Stetler-Stevenson WG, Quaranta V: Induction of cell migration by matrix metalloprotease-2 cleavage of laminin-5. Science 1997, 277:225-228.
26. Mizushima H, Koshikawa N, Moriyama K, Takamura H, Nagashima Y, Hirahara $F$, Miyazaki K: Wide distribution of laminin-5 gamma 2 chain in basement membranes of various human tissues. Horm Res 1998, 50(Suppl 2):7-14.

27. Burgeson RE, Chiquet M, Deutzmann R, Ekblom P, Engel J, Kleinman $H$ Martin GR, Meneguzzi G, Paulsson M, Sanes J, et al: A new nomenclature for the laminins. Matrix Biol 1994, 14:209-211.

28. Pyke C, Kristensen P, Ralfkiaer E, Eriksen J, Dano K: The plasminogen activation system in human colon cancer: messenger RNA for the inhibitor PAl-1 is located in endothelial cells in the tumor stroma. Cancer Res 1991, 51:4067-4071.

29. Kohlberger $P$, Beneder C, Horvat R, Leodolter S, Breitenecker G: Immunohistochemical expression of laminin-5 in cervical intraepithelial neoplasia. Gynecol Oncol 2003, 89:391-394.

30. Lenander C, Habermann JK, Ost A, Nilsson B, Schimmelpenning H, Tryggvason K, Auer G: Laminin-5 gamma 2 chain expression correlates with unfavorable prognosis in colon carcinomas. Anal Cell Pathol 2001, 22:201-209.

31. Pisani P, Parkin DM, Ferlay J: Estimates of the worldwide mortality from eighteen major cancers in 1985. Implications for prevention and projections of future burden. Int J Cancer 1993, 55:891-903.

32. Vizcaino AP, Moreno V, Bosch FX, Munoz N, Barros-Dios XM, Parkin DM: International trends in the incidence of cervical cancer: I. Adenocarcinoma and adenosquamous cell carcinomas. Int J Cancer 1998, 75:536-545.

33. Zreik TG, Chambers JT, Chambers SK: Parametrial involvement, regardless of nodal status: a poor prognostic factor for cervical cancer. Obstet Gynecol 1996, 87:741-746.

34. Alfsen GC, Thoresen SO, Kristensen GB, Skovlund E, Abeler VM: Histopathologic subtyping of cervical adenocarcinoma reveals increasing incidence rates of endometrioid tumors in all age groups: a population based study with review of all nonsquamous cervical carcinomas in Norway from 1966 to 1970,1976 to 1980 , and 1986 to 1990 . Cancer 2000, 89:1291-1299.

35. Imura J, Ichikawa K, Takeda J, Fujimori T: Beta-catenin expression as a prognostic indicator in cervical adenocarcinoma. Int J Mol Med 2001, 8:353-358

doi:10.1186/1746-1596-7-105

Cite this article as: Imura et al.: Laminin-5 is a biomarker of invasiveness in cervical adenocarcinoma. Diagnostic Pathology 2012 7:105.

\section{Submit your next manuscript to BioMed Central and take full advantage of:}

- Convenient online submission

- Thorough peer review

- No space constraints or color figure charges

- Immediate publication on acceptance

- Inclusion in PubMed, CAS, Scopus and Google Scholar

- Research which is freely available for redistribution 